\title{
DEVELOPMENT OF DYNAMIC VIDEO RECORDING SURVEILLANCE SYSTEM
}

\author{
Pratik.V.Gangurde ${ }^{1}$, S.S.Ohol ${ }^{2}$ \\ ${ }^{1}$ Student, Second Year M.Tech Mechatronics, College of Engineering Pune, Maharashtra, India \\ ${ }^{2}$ Associate professor, Department of Mechanical Engineering, College of Engineering Pune, Maharashtra, India
}

\begin{abstract}
This paper deals with development of Dynamic Video Recording Surveillance System(DVRSS). It is designed to be used for surveillance of uncontrolled situations such as riot, using a high definition camera extending out from a bullet proof car through an opening provided on the roof of the car. In case of uncontrolled or chaotic situations the forces assigned to control it mostly gets into danger as the situation goes out of control. The aim of this project is to develop DVRSS which will capture the whole situation in video form and store or telecast it in order to identify the culprits. The system consists of a high definition camera for video recording which will be deployed through the roof of the vehicle at some height. A novel technology of using rack and pinion for extension of telescopic mast is also introduced. The camera movement is controlled automatically according to the signals from user interface. The controller used is raspberry pi 2.
\end{abstract}

Keywords: Surveillance, Camera Movement Control, Telescopic Mast Deployment Using Rack And Pinion.

\section{INTRODUCTION}

In the an uncontrollable situation such as riot there can be a huge mob disturbing the public peace and causing loss of life and property. The number of people in the riot are most of the time more than the available police force who are assigned to control the riot and the force may not be able to control and can themselves get in trouble. The mob may attack the officials and as there is no evidence of them doing so, may escape.

If some camera man is taken along for the video recording the mob attacks the same and destroys the evidence. To prevent from such situation and to get strong evidence against the culprit a DVR extending out of the upper opening door provided in a bullet proof car is applied. To protect the camera from any damage caused by the angry and afraid people by throwing stones on it, the camera is protected with a dome of bullet proof glass. The DVR is extended from the inside floor of the car to a height of 12 feet from the base of the DVR with the help of 3 stage telescopic mast, the mast will be extended by a new mechanism which will contain rack and pinion arrangement which will be explained in design part.

\subsection{Scope Of Work}

The mechanism is developed to help the police force or other law enforcement officials to safely survey the riot zone without any harm caused to the official person and to safely detect and identify the cause of the mass distraction or the "culprit" causing the riot. It can help to gather video evidence against all the people participating in the riot and causing harm to others. This will have a strong proof against the people who will later deny the fact that they were present at that place and get them arrested. The mechanism can also be used in daily safety patrolling and day time surveillance of the city by the police during the patrolling period. The DVR can also prove useful in finding out the root cause of a heavy traffic as the range of the HD camera is approximately around $2 \mathrm{~km}$, anything in this range can be visible easily, this can help in locating an accident and look the severity of it and search the shortest and the fastest path to reach the location. It can also be used to find stuck people in a building in case of emergency evacuation. The DVR can be proved useful in the night time, if night vision and infrared camera are used the night patrolling unit of police can notice presence of any even when not visible by human eyes.

\section{DESIGN}

The DVR is extended from the inside base of the car to a height of 12 feet with the help of 3 stage telescopic mast. It will be extended by a new mechanism which will contain rack and pinion arrangement. The pinion will be driven using high torque dc motors. Rack will be welded to the second and third stage of the mast. A pinion is mounted on first and second stage which engages with the rack and brings out extension and retraction of the mast. The camera will be rotated by another dc motor in $360^{\circ}$. The motors control and the interface and recording of from the camera will be done with the help of Rasberry pi2b board.

Image processing device is a high resolution camera. The camera is attached at a pan device. Pan device may be any conventional device for rotating the camera three hundred and sixty degrees about the longitudinal axis of mast. A cable line which would be an interface between the rotation control system and the camera will extend with the telescopic mast and will be wound around a cable coiling mechanism. 
A rough model or first iteration of the proposed model is as shown in the figures below. Figure 1 shows the CATIA model of mast in extended position whereas figure 2 shows CATIA model of mast mounted on a vehicle in retracted position.

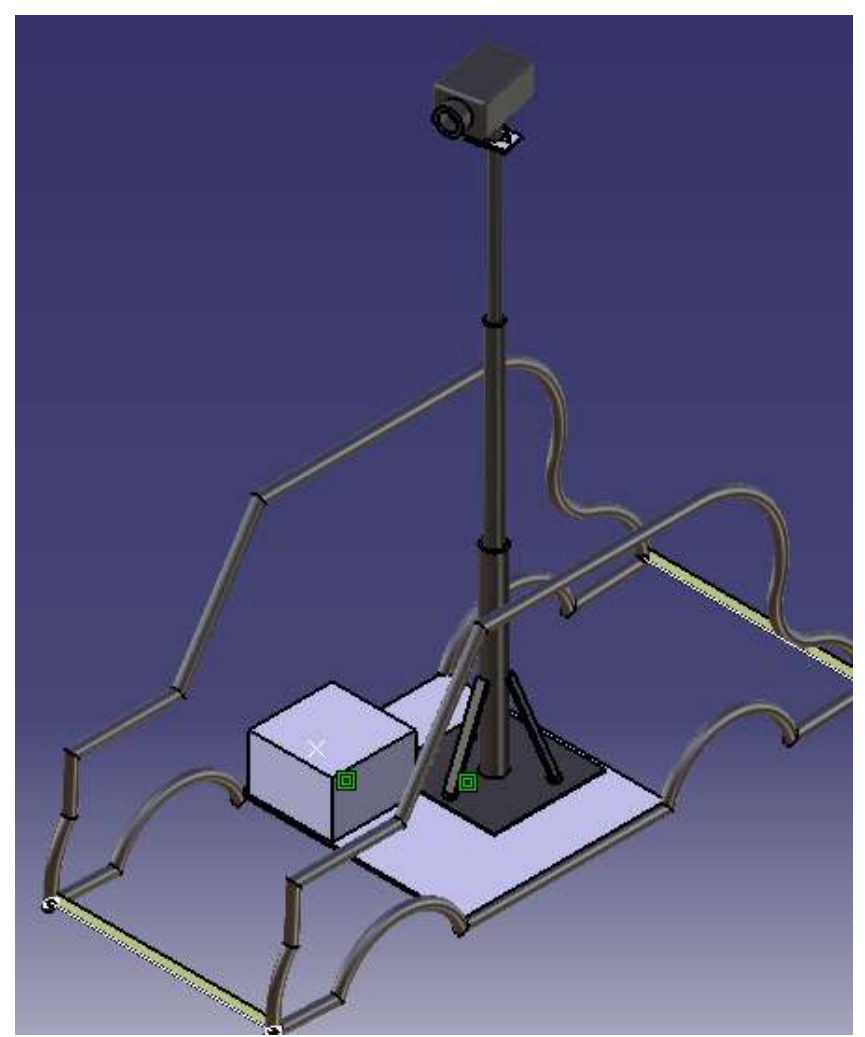

Fig -1: CATIA model of mast in extended position

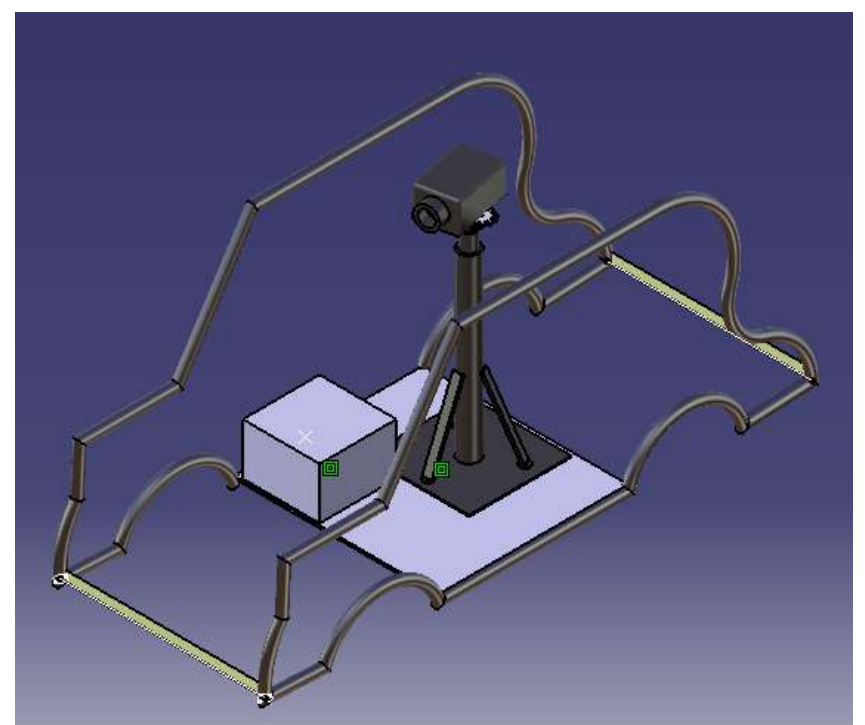

Fig -2: CATIA model of mast in retracted position

\subsection{Final Catia Model}

For the ease of manufacturing a rectangular cross section is preferred for the mast. Also due to presence of other elements like rack and pinion the diameter of circular cross section increases considerably. On the other hand the design of system with rectangular cross section becomes compact.
Hence a rectangular cross section is chosen. A $5 \mathrm{~mm}$ thick Mild steel sheet is used for mast structure. The CATIA model of the mast is shown in figure 3. Slots are produced in the upper two plates for weight reduction. ${ }^{[1]}$

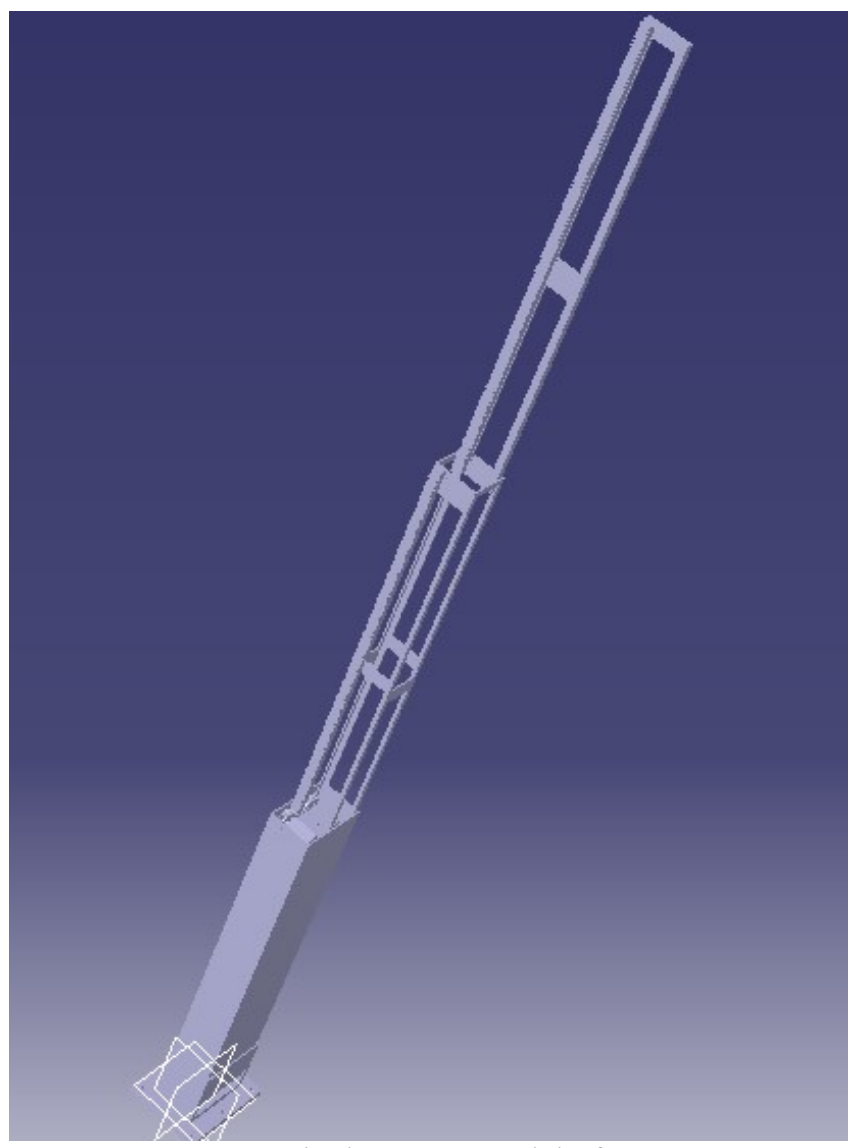

Fig -3: Final CATIA model of mast

\subsection{Wind Drag Force On The Cylinder Mast}

\section{Calculation}

As the vehicle is moving the mast experiences drag force. The drag force is to be calculated for design of rigid structure. The data required for the calculation of drag force is as follows:

Average wind speed in India $=5 \mathrm{~m} / \mathrm{s}$

Considering vehicle speed in extreme conditions $=60 \mathrm{~km} / \mathrm{hr}$ $=60 \times 5 / 18 \mathrm{~m} / \mathrm{s}=17 \mathrm{~m} / \mathrm{s}$.

Drag force acting due to wind on cylinder

$\mathrm{F}_{\mathrm{d}}=1 / 2 \rho \mathrm{v}^{2} \mathrm{Cd} \mathrm{A}$

$\rho=$ density of air $=1.2754 \mathrm{~kg} / \mathrm{m}^{3}$

$\mathrm{Cd}=$ drag coefficient $=1.2$

$\mathrm{V}=$ speed of object relative to fluid,

$\mathrm{V}=$ vehicle speed - air speed

$\mathrm{F}_{\mathrm{d}}=80 \mathrm{~N}^{[2]}$

\subsection{Design of Column for Mast}

The slenderness ratio of this Mild Steel column is 15.44. hence it acts as short column. Hence we use Rankine's short column formula.

The cross section of bottom column is $135.5 \times 210 \times 5 \mathrm{~mm}$ thick 
The area of cross section of column is given as:

$\mathbf{A}=\mathbf{L}_{\mathbf{1}} \times \mathbf{B}_{\mathbf{1}}-\mathbf{L}_{\mathbf{2}} \times \mathbf{B}_{\mathbf{2}}$

$\mathrm{A}_{\mathrm{B}}=3355 \mathrm{~mm}^{2}$

The moment of inertia of section is given as:

$I_{B}=b_{1} \frac{d_{1}{ }^{3}}{12}-b_{2} \frac{d_{2}{ }^{3}}{12}$

$\mathrm{I}_{\mathrm{B}}=20.91 \times 10^{6} \mathrm{~mm}^{4}$

Radius of gyration:

$\mathbf{K}=\sqrt{\mathbf{I} / \mathbf{A}}$

$\mathrm{K}_{\mathrm{B}}=78.95 \mathrm{~mm}$.

Length of column ' $\mathrm{l}$ ' is $4 \mathrm{ft}$.

Compressive yeild stress for Mild Steel is $276 \mathrm{MPa}$.

young's modulus for Mild Steel is $205 \mathrm{GPa}$.

According to Rankine's formula the critical load for this column is given by:

$$
F_{c r}=\frac{\sigma_{c} \times A}{1+\frac{\sigma_{c}}{\pi^{2} E} \times\left(\frac{l}{k}\right)^{2}}
$$

Substituting above values in Rankine's formula we get:

$\mathrm{Fcr}_{\text {bottom column }}=896.81 \times 10^{3} \mathrm{~N}$

The cross section of middle $\&$ top column are $115.5 \times 125 \times 5$ $\mathrm{mm}$ thick \& $20 \times 114.5 \times 5 \mathrm{~mm}$ thick

Similarly,

The values of crippling load for middle and top column of mast are as follows:

$\mathrm{Fcr}_{\text {middle column }}=585.79 \times 10^{3} \mathrm{~N}$

$\mathrm{Fcr}_{\text {top column }}=294.12 \times 10^{3} \mathrm{~N}$

The value of crippling load is more than the actual load.

Hence the column is safe. ${ }^{[3]}$

\subsection{Gear Design}

In the DVR a standard gear(pinion) of following specifications is used for lifting the rack welded to the mast. Pitch circle diameter $=55 \mathrm{~mm}$.

module $=2.5 \mathrm{~mm}$.

number of teeth $=22 \mathrm{~mm}$.

width of tooth $=20 \mathrm{~mm}$.

circular pitch $=7.85 \mathrm{~mm}$.

According to AGMA standards, bending stress on gear is given by:

$$
\sigma=\frac{F t \times K v \times K o \times K}{b \times m \times J}
$$

Where,

$\sigma=$ Bending stress on gear

$\mathrm{J}=$ Lewis modified form factor

$\mathrm{m}=$ module

$\mathrm{Kv}=$ velocity factor $=1.25$

$\mathrm{Ko}=$ overload factor $=1.25$

$\mathrm{Km}=$ load distribution factor $=1.6$

$\mathrm{Ft}=10 \mathrm{Kg}=10 \times 9.8=98 \mathrm{~N}$

$\therefore \sigma=1.47 \mathrm{~N} / \mathrm{mm}^{2}$

Permissible Stress on gear is given by:

$$
\sigma_{e}=\sigma_{e}^{\prime} \times K l \times K v \times K s \times K r \times \quad \times K f \times K m
$$

Where,

$\sigma_{e}^{\prime}=$ endurance limit of rotating-beam specimen

$\mathrm{Kl}=$ load factor $=1$ for bending load

$\mathrm{Kv}=$ size factor, $=1$ for $\mathrm{m}<5$

$\mathrm{Ks}=$ surface factor $=0.785$

$\mathrm{Kr}=$ reliability factor $=0.702$

$\mathrm{Kt}=$ temperature factor $=1$ for temperature $<350^{\circ} \mathrm{C}$

$\mathrm{Km}=$ factor of miscellaneous effects $=1.33$

therefore, permissible bending stress,

$$
\sigma_{e}=249.19 \mathrm{~N} / \mathrm{mm}^{2}
$$

This permissible bending stress is greater than actual working stress.

Hence design is safe. ${ }^{[4][5]}$

\subsection{Motor Torque Calculation}

Force required to lift to $10 \mathrm{~kg}$

$\mathrm{F}=\mathrm{mg}$,

$\mathrm{F}=98.1 \mathrm{~N}$

Torque $=\mathrm{F} \times \mathrm{d}$

$\mathrm{T}=2.69775 \mathrm{Nm}$

$\mathrm{T}=13.5 \mathrm{Nm}$ (considering factor of safety 5$)$.

$\mathrm{T}=137.66 \mathrm{~kg} \mathrm{~cm}$.

\subsection{Electronic Components}

The electronic part of the system consists of a camera mounted on a pan device which is rotated using a DC motor. The motor rotation is controlled using raspberry pi 2 . A user interface is made using raspberry pi 2 in combination with 7 inch LCD screen and inovera mini wireless key board with touchpad. The programming language used for raspberry pi 2 is python. Two DC motors with $140 \mathrm{~kg} \mathrm{~cm}$ torque are used to drive the pinion. $12 \mathrm{~V}$ lithium ion batteries are used for driving motors.

\subsection{Manufacturing and Assembly}

The set up is bolted to the car chassis. The mast is made out of mild steel. The columns are of the mast are welded from $5 \mathrm{~mm}$ thick mild steel sheet. Slots are provided in the columns using laser cutting for weight reduction. Rack is welded to the middle and top columns of the mast. The material used for rack and pinion is EN19. Figure 8 shows the top view of assembly.

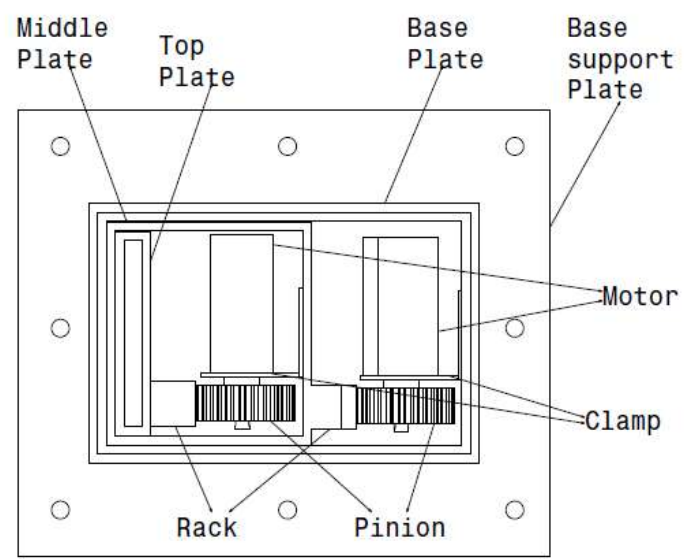

Fig -8: Top view of final assembly 


\section{CONCLUSIONS}

This paper proposes a novel way of deployment of telescopic mast. It eliminates the need of hydraulic or pneumatic system which is inconvenient for use in portable equipments. It is also compact as compared to the fluid power systems as no reservoirs and other complementary components are required. It is low cost and power efficient. It performs the intended application efficiently.

\section{ACKNOWLEDGEMENT}

Authors acknowledge the help received from Alumni Association, College of Engineering, Pune for kind support, Mr. Vijay Kare, Pune.

\section{REFERENCES}

[1]. Sham Tickoo, Purdue university, Calumet and CADCIM technologies,USA, CATIA V5R21 for designers, ISBN:978-1-936646-13-5.

[2]." R K Bansal', Firewall media, A Text Book of Fluid Mechanics and Hydraulic machines,(2005) (501) ISBN:8131802949.

[3]."P C Gope", PHI learning Pvt. Ltd., Machine DesignFundamentals and applications(2012) (79-81) ISBN:987-81203-4517-1

[4]. "GM MAITRA, McGraw Hill 2nd edition, Handbook of gear design,(4sep 2001) 536.

[5]. "Shigley's, Richard G.budynas, J.Keith nisbett, McGraw Hill 10thedition, mechanical engineering design (1 Feb 2014)(1104).

\section{BIOGRAPHIES}

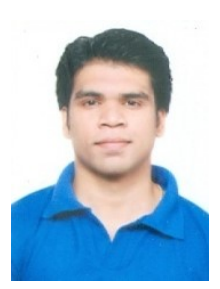

Pratik V Gangurde,

Author is post graduate student of mechatronics in College of Engineering, Pune, India and has pursued bachelors degree in production engineering at $\mathrm{K}$. K. Wagh, Nashik.

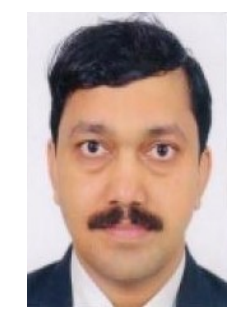

\section{Dr. Shantipal Ohol,}

Faculty in Mechanical Engineering Department, College of Engineering Pune, Industrial Experience of 1.7 Yrs. Teaching Experience of 14 Yrs Incharge of Centralized Robotics and Automation Laboratory in the Institute. Associate Professor at COEP. 